\title{
PENAMPILAN DAN PRODUKSI PADI LADANG LOKAL VARIETAS 100 MALAM
}

\section{Appearance and Production of 100 Night Variety Local Rice}

\author{
Apresus Sinaga, Sostenes Konyep, Steven Witman, dan Igit Atang Sunante \\ Balai Pengkajian Teknologi Pertanian Papua Barat \\ e-mail: apresusnaga@gmail.com
}

Received: 22 November 2021; Accepted: 27 Desember 2021; Published: 28 Desember 2021

\begin{abstract}
ABSTRAK
Padi gogo merupakan tanaman yang mempunyai kelebihan secara agrosistem dan produksi padi gogo dapat meningkatkan penambahan produktivitas padi secara nasional. Kegiatan dilaksanakan di Kampung Mandrat, Distrik Warmare, Kabupaten Manokwari, Papua Barat pada bulan Oktober 2020 - bulan Maret 2021. Komponen agronomi yang diamati meliputi tinggi tanaman, jumlah anakan, panjang malai, jumlah gabah, jumlah gabah berisi dan berat gabah. Data pengamatan dianalisis menggunakan analisis korelasi untuk menduga hubungan keeratan antar karakter kuantitatif. Untuk melihat besarnya pengaruh masingmasing faktor tinggi tanaman, jumlah anakan, panjang malai, jumlah gabah, dan jumlah gabah berisi terhadap berat gabah digunakan analisis regresi berganda dengan fasilitas automatic linear modeling. Hasil kegiatan menunjukkan Rata-rata tinggi tanaman padi lokal varietas 100 malam sebesar $154,2 \mathrm{~cm}$ dan ratarata berat gabah per malai sebesar 1,29 gr. Hasil analisis korelasi, terdapat pengaruh yang signifikan antara variabel tinggi tanaman dan gabah berisi terhadap berat gabah. Hasil analisis regresi antar komponen menunjukkan terdapat hubungan yang sangat signifikan positif antara jumlah gabah $(\mathrm{R}=0,84 * *)$ dan jumlah gabah berisi $(\mathrm{R}=0,99 * *)$ terhadap berat gabah padi.
\end{abstract}

Kata Kunci: Komponen variabel, analisis regresi berganda, produksi padi gogo

\section{ABSTRACT}

Upland rice is a plant that has advantages in agrosystems and Upland rice production can increase the increase in rice productivity nationally. The activity was carried out in Mandrat Village, Warmare District, Manokwari Regency, West Papua in October 2020 - March 2021. Komponen agronomi yang diamati meliputi tinggi tanaman, jumlah anakan, panjang malai, jumlah gabah, jumlah gabah isi dan bobot gabah. Observational data were analyzed using correlation analysis to estimate the close relationship between quantitative characters. To see the magnitude of the influence of each factor on plant height, number of tillers, panicle length, number of grain, and number of filled grain on grain weight, multiple regression analysis was used with automatic linear modeling facilities.The results of the activity showed that the average height of the 100 Malam variety of local rice was $154.2 \mathrm{~cm}$ and the average grain weight per panicle was $1.29 \mathrm{gr}$. The results of the correlation analysis, there is a significant effect between the variables of plant height and the amount of grain on grain weight. The results of the inter-component regression analysis showed that there was a very significant positive relationship between the amount of grain $\left(R=0.84^{* *}\right)$ and the amount of unhulled grain $\left(R=0.99^{* *}\right)$ on the weight of the rice grain.

Keywords: Variable component, multiple regression analysis, upland rice production

\section{PENDAHULUAN}

Kebutuhan pangan terutama beras yang begitu tinggi sehingga perlu upaya peningkatan produksi beras harus dilakukan, baik melalui upaya ekstensifikasi maupun intensifikasi
(Hasrawati, Kadekoh, \& Ete, 2017). Hasil perhitungan spasial menggunakan peta tanah tinjau dan kriteria penentuan lahan kering, luas lahan kering di seluruh Indonesia mencapai 144,47 juta ha atau $76,20 \%$ dari luas daratan 
Indonesia (Ritung, at. al. 2015). Luas lahan kering diatas sebenarnya dapat dimaafkan untuk ekstensifikasi pertanaman pangan, khususnya padi gogo, agar produktivita padi nasional dapat meningkat. Lahan kering berpotensi sebagai sumber daya tanah yang dapat dimanfaatkan untuk ekstenfikasi padi gogo (Hajoeningtijas \& Purnawanto, 2013).

Komoditas padi gogo kurang diminati patani khususnya petani di kabupaten Manokwari. Petani yang menanam padi gogo di Kabupaten Manokwari terbilang kecil, petani yang menanam padi gogo lokal hanya dibeberapa petani di beberpa kampung di Kabupaten Manokwari. Petani kurang berminat menanam padi gogo karena produksinya padi gogo lebih rendah dari hasil produksi padi irigasi. Hal ini didukung laporan dari BPS (2018), bahwa produksi rata-rata nasional padi irigasi sebesar 53.54 KU sedangkan produksi rata-rata padi gogo sebesar $32.81 \mathrm{KU}$.

Rumintjap \& Muis (2014) mengatakan produksi padi dapat meningkat apabila mengoptimalkan input produksi melalui perbaikan teknologi budidaya, baik penggunaan pupuk, penggunaan benih, ketersediaan tenaga kerja, dalam meningkatkan produktivitas. Munawwarah \& Nurbani (2016), mengatakan bahwa tanaman padi gogo memiliki kelebihan antaranya berfungsi sebagai tanaman pioneer, dapat ditanam tanpa olah tanah, tanaman dapat memanfaatkan hara secara efisien dan toleran terhadap $\mathrm{pH}$ tanah rendah, biaya produksi dan tenaga kerja relative rendah, tidak membutuhkan air yang besar, budidaya padi gogo tidak memerlukan teknologi tinggi dan dapat ditumpang sarikan dengan tanaman lain.

Petani di kampung Warmer, Kabupaten Manokwari selalu menanam padi gogo varietas lokal (padi gogo varietas 100 malam) yang ditanam sekali dalam setahun. Oleh karena itu perlu dilakukan kegiatan untuk mengetahui penampilan dan melihat hubungan antar karakter komponen tanaman terhadap karakter hasil dengan analisis regresi serta melihat potensial hasil padi varietas 100 malam yang adaptif.

\section{METODE PENELITIAN}

\section{Tempat dan Waktu Penelitian}

Pengkajian dilaksanakan di Kampung
Mandrat, Distrik Warmare, Kabupaten
Manokwari, Papua Barat pada bulan Oktober 2020 - bulan Maret 2021.

\section{Bahan dan Alat}

Pengkajian mengggunakan bahan diantaranya benih padi varietas 100 malam, Alat yang digunakan antara lain cangkul, Ani-ani, parang, ember, kayu untuk tugal alat tulis menulis dll.

\section{Metode dan Analisis}

Pengkajian dilaksanakan secara on farm dilahan petani dengan menggunakan pendekatan partisipatif.

\section{Pelaksanaan Penelitian}

Lahan yang digunakan adalah lahan bekas kebun yang sudah beberapa lama telah diberakan. Lahan dibersihkan dengan cara pohon-pohon ditebang kemudian dibiarkan hingga tanaman mengering. Semua tanaman yang sudah mengering dibakar sampai lahan tampak bersih dari sisa-sisa tanaman. Penanaman padi gogo dilakukan tanpa olah tanah, penanaman dilakukan setelah hujan turun.

Penanaman pagi gogo dilakukan dengan cara ditugal, jumlah benih sebanyak 2-5 per lubang tanam. Penaman padi dilakukan padi pagi hari, biasanya pria yang menugal dan Wanita yang menanam. Setelah kurang lebih 2 minggu lahan dibersihkan dari gulma. Tanaman padi gogo varietas 100 malam yang ditanam masyarakat local tanpa diberi pupuk dan tanpa Penanaman dilakukan dengan cara ditugal, tanaman selama masa pertumbuhan sampai hasil tanpa diberi pupuk dan tanpa dilakukan pengendalian secara kimia.

Setelah tanaman padi gogo varietas 100 malam menguning lebih dari $90 \%$ maka tanaman akan siap dipenen. Petani lokal biasanya memanen tanaman padi gogo menggunakan aniani. Hasil panen padi gogo terlebih dahulu disimpan di gudang penyimpanan yang terhindar dari berbagai gangguan hewan.

\section{Pengamatan dan Analisa Data}

Komponen pertumbuhan yang diamati adalah tinggi tanaman, jumlah anakan, panjang malai, jumlah gabah, jumlah gabah berisi dan berat gabah. Analisis korelasi digunakan untuk menduga hubungan keeratan antar karakter kuantitatif. Untuk lebih mengetahui besarnya pengaruh masing-masing faktor tinggi tanaman, 
jumlah anakan, panjang malai, jumlah gabah, dan jumlah gabah berisi (variabel independen) tersebut terhadap berat gabah (dependen) digunakan analisis regresi berganda dengan fasilitas automatic linear modeling pada SPSS 23 (Santoso, 2016).

\section{HASIL DAN PEMBAHASAN}

\section{Komponen Pertumbuhan}

Rata-rata tinggi tanaman padi lokal varietas 100 malam sebesar 154,2 cm (Gambar. 1). Tinggi tanaman padi varietas 100 lebih tinggi dari rata- rata tinggi tanaman varietas inpago 5 inpago 8, inpago 9, inpari 19 dan vareitas umbul dimana rata-rata tertinggi dari ke-5 varietas yang dikaji menunjukkan rata-rata tertinggi adalah varietas inpago 8 (Jauhari at. al. 2020).

Gambar 1, menunjukkan rata-rata jumlah anakan padi lokal varietas 100 malam, sebanyak 14,8 buah. Hasil jumlah anakan varietas local padi 100 malam lebih tinggi dibandingkan padi gogo varietas inpago 9 dengan hasil jumlah anakan sebesar 12,8 (Sudarmawan, Rosadi, \& Triyono, 2017).

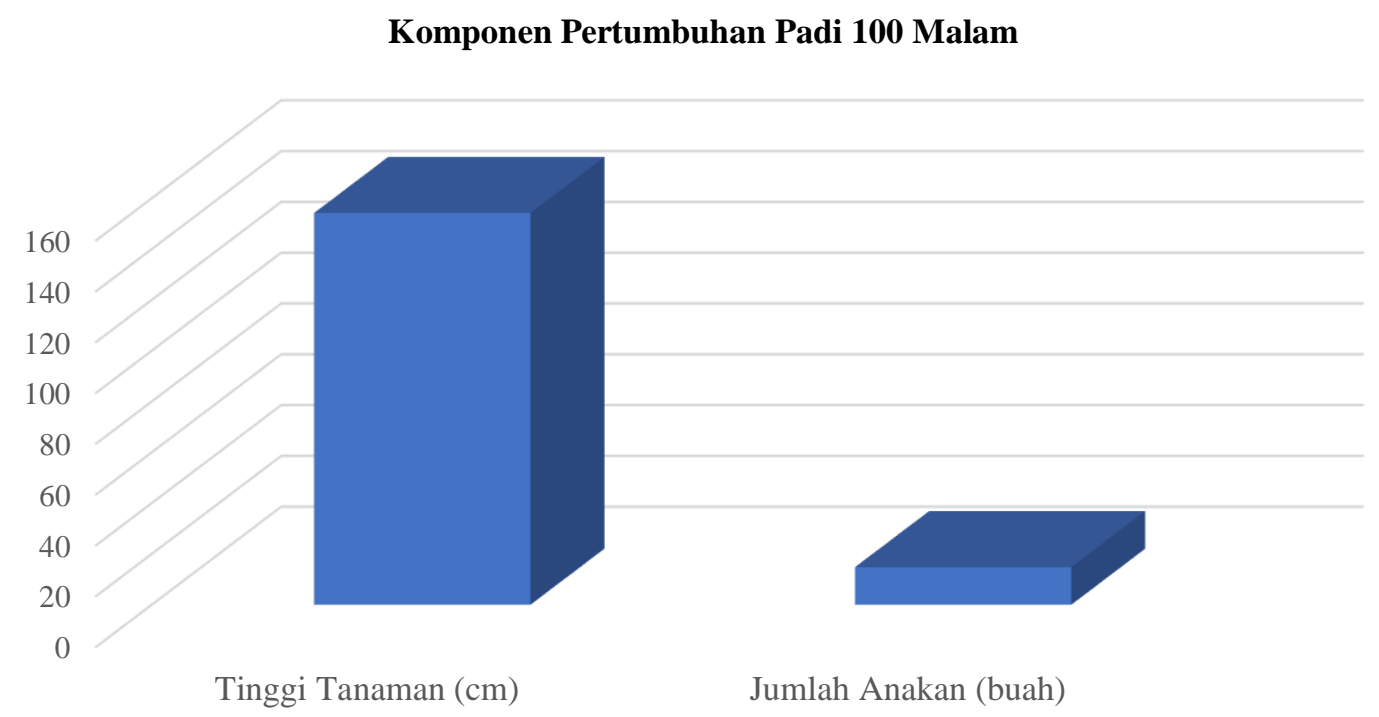

Gambar 1. Grafik tinggi tanaman dan jumlah anakan varietas padi 100 malam

\section{Komponen Hasil}

Pengamatan komponen hasil padi varietas lokal 100 malam yang berasal dari kecamatan warmare, Kabupaten Manowari, Provinsi Papua Barat menunjukkan rata-rata hasil panjang malai adalah 20,6 cm (Gambar. 2). Hasil rata-rata panjang malai padi gogo varietas 100 malam lebih rendah dari hasil padi gogo varietas inpago 4, inpago, 5 dan inpago 8 dari hasil penelitian Nazirah \& Damanik (2015).

Pada gambar 2 menunjukkan rata-rata jumlah gabah per malai sebesar 88,45 buah, Jumlah gabah isi per malai rata-rata sebesar 57,54 buah dan rata-rata berat gabah per malai sebesar 1,29 gr. Hasil penelitian Fadhilah, Karno \& Kristanto (2021) melaporakan bahwa jumlah biji padi varietas inpago Unsoed 1 sebesar 229 buah. Edi (2013) melaporkan hasil gabah bernas berturut-turut padi varietas inpago 4, inpago 5 dan inpago 6 sebesar 65,51 gr, 66,27 gr, dan 74,26 gr.

\section{Hubungan antar Komponen Pertumbuhan terhadap Produksi Gabah}

Hasil analisi korelasi antar komponen menunjukkan terdapat pengaruh yang signifikan antara variabel tinggi tanaman dan gabah berisi terhadap berat gabah, nilai tingkat signifikan tinggi tanaman dan gabah berisi sebesar 0,001 dan 0,033. Karakter tinggi tanaman berkorelasi positif dan nyata dengan karakter jumlah anakan produktif per rumpun, jumlah gabah total per malai, persentase gabah isi per malai (Riyanto, Widiatmoko \& Hartanto, 2012).

Hasil gambar 3, memperlihatkan terdapat hubungan yang sangat signifikan positif antara jumlah gabah sebesar $\mathrm{R}=0,84^{* *}$ dan jumlah 
gabah berisi sebesar $\mathrm{R}=0,99 * *$ terhadap berat gabah (Table. 2). Hasil penelitian Afa, at. al. (2021) melaporkan bahwa komponen hasil gabah berkorelas positif terhadap bobot bobot gabah isi dan terhadap berat gabah per rumpun dengan nilai sebesar $0,92^{*}$ dan $0,83^{*}$.

\section{Komponen Hasil Padi Varietas 100 Malam}

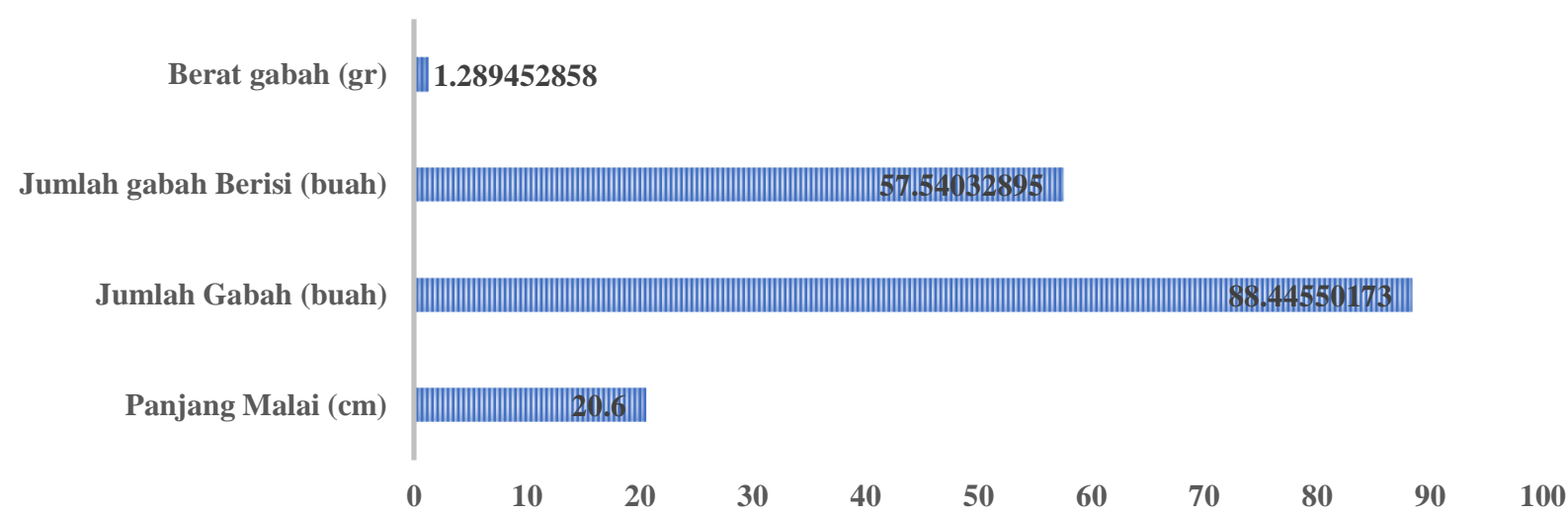

Gambar 2. Grafik jumlah rata-rata berat gabah, jumlah gabah berisi, jumlah gabah, dan pajang malai padi 100 malam

Tabel 1. Rata-rata tinggi tanaman, jumlah anakan, panjang malai, jumlah gabah, jumlah gabah berisi dan berat gabah

\begin{tabular}{lllllll}
\hline & TT $(\mathrm{cm})$ & JA (buah) & PM (cm) & JG (buah) & JGB (buah) & BG (gr) \\
\hline TT (cm) & 1,00 & & & & & \\
JA (buah) & 0,26 & 1,00 & & & & \\
PM (cm) & 0,23 & 0,43 & 1,00 & & & \\
JG (buah) & $0,76^{*}$ & 0,47 & 0,53 & 1,00 & & \\
JGB (buah) & 0,43 & 0,18 & 0,58 & $0,84^{* *}$ & 1,00 & \\
BG (gr) & 0,52 & 0,14 & 0,56 & $0,84^{* *}$ & $0,99 * *$ & 1,00 \\
\hline
\end{tabular}

Ket : TT = Tinggi Tanaman; JA = Jumlah Anakan; PM = Panjang Malai; JG = Jumlah Gabah; JGB = Jumlah gabah Berisi; $\mathrm{BG}=$ Berat gabah

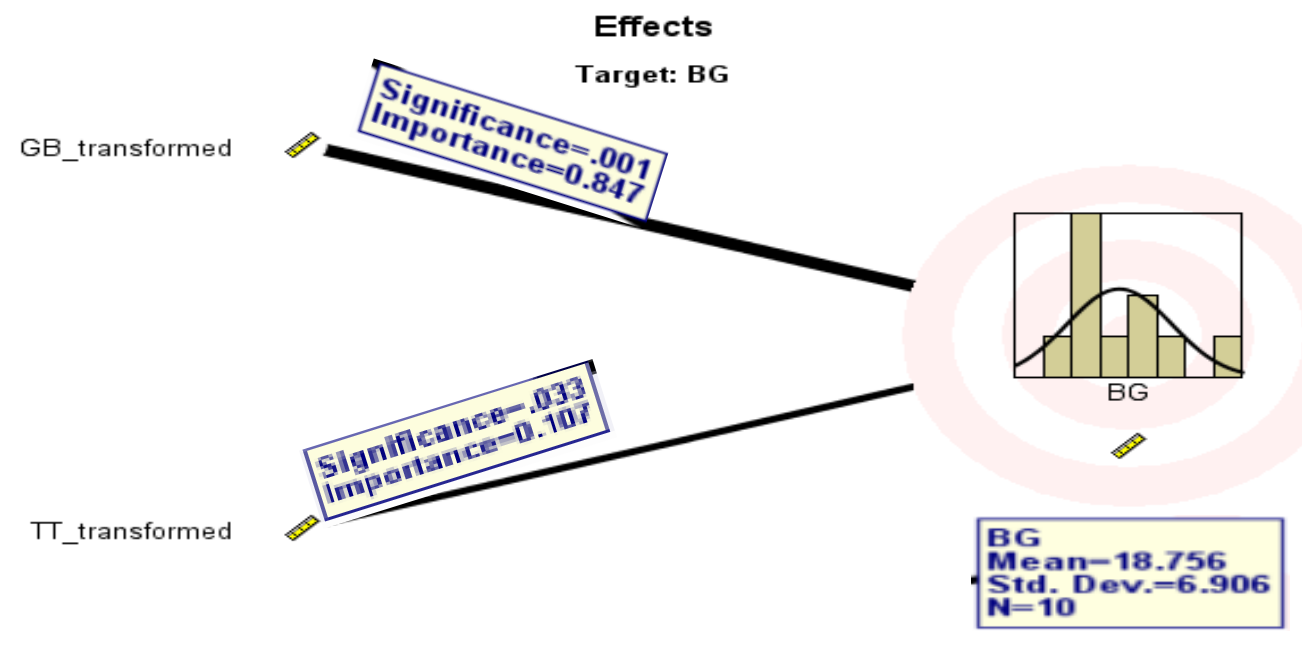

Gambar 3. Grafik Uji Koefisien Regresi Individu (GB= Berat Gabah, GB = Gabah Berisi dan TT = Tinggi Tanaman) secara Visual pada Taraf Signifikan 0,05 
Pengaruh gabah berisi terhadap berat gabah sebesar $87,70 \%$ sedangkan pengaruh tinggi tanaman terhadap berat gabah sebesar 10,70 \% (Gambar. 3). Safitri (2011) mengatakan bahwa peningkatan jumlah gabah total dan gabah isi per malai secara signifikan akan meningkatkan hasil biji per rumpun.

\section{KESIMPULAN}

Hasil analisi korelasi antar komponen menunjukkan terdapat pengaruh yang signifikan antara variabel tinggi tanaman, jumlah gabah dan gabah berisi terhadap berat gabah.

\section{UCAPAN TERIMA KASIH}

Penulis mengucapkan terima kasih kepada penyuluh daerah dan bapak ibu petani lokal di Warmare, Kabupaten Manokwari, Provinsi papua barat.

\section{DAFTAR PUSTAKA}

Riyanto, A., T. Widiatmoko \& B. Hartanto (2012). Korelasi Antar Komponen Hasil Dan Hasil Pada Padi Genotip F5 Keturunan Persilangan G39 X Ciherang. Prosiding Seminar Nasional Pengembangan Sumber Daya Pedesaan dan Kearifan Lokal Berkelanjutan II. Purwokerto. 27-28.

Badan Pusat Statistik. 2018. Produktivitas Padi Ladang Menurut Provinsi, Tahun 2014 2018.

Edi, S. (2013). Keragaan Varietas Dan Galur Harapan Padi Gogo Pada Daerah Aliran Sungai Batang Asai Sarolangun Jambi. Program Studi Agroekoteknologi, Fakultas Pertanian Universitas Jambi. 2(3).

Fadhilah, F., Karno \& B.A. Kristanto. 2021. Respon pertumbuhan dan produksi padi gogo (Oryza sativa L.) terhadap cekaman kekeringan dan pemupukan silika. J. Agro Complex 5(1):1-13.

Hajoeningtijas, O. D., \& Purnawanto, A. M. 2013. Keragaman Padi Gogo Lokal Di Kabupaten Banyumas Jawa Tengah. AGRITECH : Vol. 2: 69 - 77.

Hasrawati, A., Kadekoh, I., \& Ete, A. 2017. Karakteristik Padi Gogo Lokal Yang Diberi Bahan Organik Pada Berbagai
Ketersediaan Air. e-J. Agrotekbis 5 (2) : $134-143$.

Jauhari, S., E. Winarni, \& D. Sahara. 2020. Keragaan Pertumbuhan dan Produktivitas Padi Gogo Varietas Unggul Baru (VUB) di Lahan Sawah Tadah Hujan di Kabupaten Semarang, Jawa Tengah. PANGAN, 29 (1): 25-34.

Laode Afa, L, Suaib, I. Uge, A. A. Anas \& Maisura. 2021. Korelasi Antara Hasil dan Komponen Hasil beberapa Kultivar Padi Gogo (Oryza Sativa L.) Lokal Sulawesi Tenggara pada Dua Sistem Budidaya. Jurnal Agrium. 18(1): 9-16.

Munawwarah \& Nurbani (2016). Adaptasi VUB Padi Gogo pada Agroekosistem Lahan Kering Dataran Rendah di Kalimantan Timur. Prosiding Seminar nasional hasil -hasil PPM IPB. 112-122p.

Nazirah, L. \& B. S. J. Damanik. 2015. Pertumbuhan Dan Hasil Tiga Varietas Padi Gogo Pada Perlakuan Pemupukan. J. Floratek 10: $54-60$.

Ritung, S., E. Suryani, D. Subardja, Sukarman, K. Nugroho, Suparto, Hikmatullah, A. Mulyani, C. Tafakresnanto, Y. Sulaeman, R. E. Subandiono, Wahyunto, Ponidi, N. Prasodjo, U. Suryana, H. Hidayat, A. Priyono, \& W. Supriatna. 2015. Sumber Daya Lahan Pertanian Indonesia Luas, Penyebaran, Dan Potensi Ketersediaan. Badan Penelitian dan Pengembangan Pertanian. IAARD Press. 1-116p.

Rumintjap, V. \& Muis, A. 2014. Padi Sawah di Desa Pandere Kecamatan Gumbasa Kabupaten Sigi Provinsi Sulawesi Tengah. e-J. Agrotekbis 2 (3) : 309-316.

Safitri, H., Bambang S. Purwoko, I. S. Dewi \& B. Abdullah. 2011. Korelasi Dan Sidik Lintas Karakter Fenotipik Galurgalur Padi Haploid Ganda Hasil Kultur Antera. Widyariset, 14 (2).

Santoso, S. 2016. Panduan Lengkap SPSS Versi 23. PT. ElexMedia Komputindo. Jakarta. $1-454 \mathrm{p}$.

Sudarmawan, M., R.A. B. Rosadi, \& S. Triyono (2017). Aplikasi Irigasi Defisit Pada Padi Gogo (Oryza Sativa L.) Varietas Inpago 9. Jurnal Teknik Pertanian Lampung.6 (3): $141-150$. 